Within comparatively recent times, considerable attention has been directed towards the use of high pressures in the synthesis of organic compounds, the hydrogenation of tar and tar distillates and gaseous liquid phase reactions. The first session on Thursday morning was devoted to this subject. Included with this group of papers was one on the use of high vacua.

Few chemical engineers escape the problem of considering the transmission of heat to or the removal of heat from the product at one or more stages in the course of its manufacture. The importance of this subject therefore demanded the attention of the members during the second session on Thursday morning, when papers dealing with the evaporation of solutions liable to be affected by high temperatures, and the use of waste heat for low-temperature evaporation as well as methods by which waste heat may be recovered from intermittent sources, were under discussion.

The attendance and discussion which followed the report upon the papers on Friday morning dealing with the training of a chemical engineer indicated how this subject has been claiming the attention of both industrialists and teachers in America, Austria, Canada, France, Germany, Great Britain, Japan and the U.S.S.R.

In the session which followed were papers from Germany, Great Britain and the United States of America on administration, safety and welfare, and the statistical duties which fall to the lot of the chemical engineer in industry. These papers show how the countries concerned are taking precautionary measures to reduce accidents and occupational risks attendant upon chemical industry, and the factors which influence the choice of site for a works and the cost of the product.

Trend of development was the title allotted to the first session on Friday afternoon, at which papers were presented on a variety of subjects in which amongst others are those relating to water treatment and softening, fumigation, developments in the sulphuric acid industry and the production of concentrated fertilizers from poor phosphates. Although the papers in this group deal with many subjects, their importance to the technical worker cannot be denied, since they consider problems arising in many industries.

The organization of research stations both of a public and private character and the part which fundamental research must play in industrial organizations were the subjects of some of the papers presented at the last session, which also included other papers on rapid methods of determining the standard of the product, the standardization of chemical apparatus and its future development, as well as a number of other aspects of interest to the chemical engineer.

Sir Harold Hartley, chairman of the International Executive Council of the World Power Conference, presided on Saturday morning at the closing meeting of the Congress, at which various reports were presented. Thanks were also tendered by numerous speakers to the various committees and officers, and a striking tribute not only to the success but also to the utility of the Congress was given when it was announced that an invitation had been received from the German National Committee to hold a second International Congress on Chemical Engineering in Berlin in 1940.

\title{
Oceanic Macroplankton of the Dana Expeditions*
}

$\mathrm{D}^{\mathrm{R}}$ R. P. JESPERSEN has compared the amount of macroplankton in the various waters investigated by the Carlsberg Foundation's Oceanographical Expedition round the world in 1928-30. Volume determinations were made of 2231 pelagic hauls, distributed in eight regions-North Atlantic and Caribbean Sea, Pacific and Tasmanian Sea, Indo-Malayan region, waters west of Sumatra, Indian Ocean, South Atlantic, Straits of Gibraltar and adjacent waters, and the Mediterranean.

The paper deals solely with the purely quantitative side of the macroplankton as a whole, the only exception being a determination of the fish and fish fry of the different water layers in the regions of the Pacific : otherwise only occasional notice is taken of what organisms may be dominant-so far as volume is concerned-in the composition of the plankton. It is usually the salps which are thus noted, sometimes siphonophores, Sagitta, euphausiids and decapods.

A comparison of the microplankton on the two sides of the Panama Isthmus shows a very great difference. Thus in the upper water layers $(50-100$ metres wire) the quantity is greater in the Caribbean

* The Carlsberg Foundation's Oceanographical Expedition round the World, 1928-30, and previous Dana-Expeditions. Dana-Report plankton in different Oceanic Regions $\mathrm{By} \mathrm{P}$. Jespersen $\mathrm{Pp}$. 44 (Copenhagen $\quad$ C. A. Reitzel's Forlag; London: Oxford University Press, 1935. 7.
Sea, but in all deeper hauls the volumes are very much greater in the Gulf of Panama. It is shown that in layers corresponding to hauls with 300-600 metres wire the amount of macroplankton in the Gulf of Panama is about twice the amount in the Caribbean Sea, and in depths corresponding to hauls with 1,000-3,000 metres wire the quantities of plankton are six to eight times larger in the Gulf of Panama than in the Caribbean Sea. The remarkably rich plankton fauna in the deeper waters of the Gulf of Panama is of peculiar interest, as nowhere else in the areas of the Pacific, Indian Ocean or the South Atlantic investigated is anything like such large quantities met with. It is only in the North Atlantic at about $30^{\circ} \mathrm{N}$. that corresponding quantities of plankton are found in the deeper layers.

It is characteristic of the plankton fauna of the Gulf of Panama that it is considerably richer in the deeper than in the surface layers, a condition quite unique, since at all other places in the regions investigated the quantities of plankton are greatest in the upper layers. It may be said that, on the whole, the quantity of macroplankton in the deeper layers (hauls with at least 1,000 metres wire) is comparatively small and fairly uniform in most of the tropical and temperate oceanic regions. The one exception is the Gulf of Panama, where we find a remarkably large quantity of plankton in the deeper layers. 